\title{
MIP-1 $\alpha$ Induction by Palmitate in the Human Monocytic Cells Implicates TLR4 Signaling Mechanism
}

\author{
Rasheed Ahmad ${ }^{\mathrm{a}} \quad$ Nadeem Akhter $^{\mathrm{a}} \quad$ Areej Al-Roub $^{\mathrm{a}}$ Shihab Kochumon ${ }^{\mathrm{a}}$ \\ Ajit Wilson ${ }^{a}$ Reeby Thomas ${ }^{a}$ Shamsha Alia Jaakko Tuomilehto ${ }^{a, b}$ \\ Sardar Sindhu ${ }^{b}$ \\ almmunology Unit, Dasman Diabetes Institute, Kuwait-City, Kuwait, ${ }^{b}$ Animal and Zebrafish Core Facility, \\ Dasman Diabetes Institute, Kuwait-City, Kuwait
}

\section{Key Words}

Palmitate $\cdot$ TLR4 $\bullet$ MIP- $1 \alpha / C C L 3$

\begin{abstract}
Background/Aims: MIP-1 $\alpha$ (macrophage inflammatory protein $1 \alpha$ )/CCL3 chemokine is associated with the adipose tissue inflammation in obesity. Both MIP- $1 \alpha$ and free fatty acids are elevated in obesity/T2D. We asked if free fatty acid palmitate could modulate MIP$1 \alpha$ expression in the human monocytic cells. Methods: Human monocytic THP-1 cells and macrophages were stimulated with palmitate and TNF- $\alpha$ (positive control). MIP- $1 \alpha$ expression was measured with real time RT-PCR, Flow Cytometry and ELISA. Signaling pathways were identified by using THP-1-XBlue ${ }^{\mathrm{TM}}$ cells, THP-1-XBlue ${ }^{\mathrm{TM}}$-defMyD cells, anti-TLR4 mAb and TLR4 siRNA. Results: Our data show that palmitate induced significant increase in MIP$1 \alpha$ production in monocytic THP-1 cells/macrophages. MIP- $1 \alpha$ induction was significantly suppressed when cells were treated with anti-TLR4 antibody prior stimulation with palmitate. Using TLR4 siRNA, we further demonstrate that palmitate-induced MIP- $1 \alpha$ expression in monocytic cells requires TLR4. Moreover, THP1 cells defective in MyD88, a major adaptor protein involved in TLR4 signaling, were unable to induce MIP-1 $\alpha$ production in response to palmitate. Palmitate-induced MIP-1 $\alpha$ expression was suppressed by inhibition of MAPK, NF$\mathrm{kB}$ and PI3K signaling pathways. In addition, palmitate-induced NF-kB/AP-1 activation was observed while production of MIP- $1 \alpha$. However, this activation of NF-kB/AP-1 was abrogated in MyD88 deficient cells. Conclusion: Overall, these results show that palmitate induces TLR4dependent MIP- $1 \alpha$ expression requiring the MyD88 recruitment and activation of MAPK, NF-kB/AP-1 and PI3K signaling. It implies that the increased systemic levels of free fatty acid palmitate in obesity/T2D may contribute to metabolic inflammation through excessive production of MIP- $1 \alpha$.
\end{abstract}




\section{Cellular Physiology Cell Physiol Biochem 2019;52:212-224

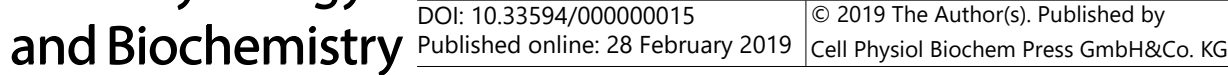 \\ Ahmad et al.: MIP-1 $\alpha$ Induction by Palmitate}

\section{Introduction}

Obesity mediated chronic low-grade inflammation plays a key role in the development of insulin resistance and metabolic syndrome. Insulin resistance may result in immune dysregulation which is a major contributor to the pathogenesis of coronary artery disease, atherosclerosis, hypertension, lipid abnormalities, diabetes etc. [1, 2]. Obesity modulates immune cells and their function. Emerging evidence supports that adipose tissue undergoes continuous remodeling in obesity and thus, dynamic changes take place in obese adipose tissue such as changes in adipocyte numbers and size, immune cell turnover as well as M2 to M1 polarization/phenotypic shift, and extracellular matrix changes to favor expandability, remodeling, and angiogenesis. Thus, obese adipose tissue abounds in inflammatory M1 macrophages which secrete a wide range of proinflammatory cytokines/chemokines. Through autocrine/paracrine effects, these inflammatory cytokines play a pivotal role in triggering low-grade chronic inflammation within the adipose tissue as well as engage in crosstalk with hypertrophied adipocytes which, in turn, secrete adipokines and exacerbate the ongoing inflammatory responses [3]. The phenomena of migration and infiltration of circulatory monocytes into adipose tissue and inflammatory sites is regulated, in a part, by chemokines. Macrophage Inflammatory Proteins (MIP) belong to chemotactic cytokines or chemokines that are subdivided into MIP-1 $\alpha$ (CCL3) and MIP-1 $\beta$ (CCL4). The chemotactic activity of these soluble factors for specific types of leukocyte populations is involved in the regulation of cell-mediated immunity by modulating the production of inflammatory cytokines [4].

MIP-1 $\alpha$ induces synthesis and release of other pro-inflammatory cytokines such as interleukin-1 (IL-1), IL- 6 and TNF- $\alpha$ from fibroblasts and macrophages. MIP- $1 \alpha$ is produced by monocytes, macrophages, lymphocytes, and other cell types [4]. Since the resident macrophages do not proliferate, circulating monocytes are the source of recruited adipose tissue macrophages (ATMs) in adipose tissue. Both activated monocytes and ATMs can contribute MIP- $1 \alpha$ levels in obesity, ATMs or more precisely inflammatory M1 macrophages, are a more well-known source of MIP- $1 \alpha$ as well as other inflammatory mediators in the white adipose tissue in obesity [5]. Increased both circulatory and adipose tissue expression of MIP- $1 \alpha$ in metabolic syndrome is well documented. However, little information is available concerning the production and regulation of MIP-1 $\alpha$ in metabolic syndrome.

Immune system function changes in obesity/T2D lead to the increased production of free fatty acids (FFAs) [6]. A mechanistic link between the FFAs and the innate immune tolllike receptors (TLRs) is shown in metabolic syndrome. TLRs belong to a family of pattern recognition receptors that sense the pathogen-associated molecular patterns such as proteins, lipids, lipoproteins, and FFAs [7]. After binding with ligand(s), TLRs may engage various downstream factors including Toll/Interleukin-1 receptor (TIR) domain-containing myeloid differentiation factor 88 (MyD88), MyD88 adaptor-like (MAL) protein, TIR domaincontaining adaptor protein inducing IFN $\beta$ (TRIF) and TRIF-related adaptor molecule (TRAM). This association triggers the formation a macromolecular complex containing IRAK1, TNF- $\alpha$ receptor-associated factor 6 (TRAF6) as well as activating transcription factors NF- $\kappa \mathrm{B}$ and AP-1[8-10]. FFAs activate TLR4-mediated signaling for the production of proinflammatory cytokines/chemokine by various immune cells. Induction of such inflammatory responses has been linked to high fat diet-induced insulin resistance in the adipose tissue and skeletal muscle [11]. In obesity, the most abundant saturated fatty acid palmitate was shown to induce proinflammatory cytokines including TNF- $\alpha$, IL-6 and IL-8 [12-14]. We have previously shown that palmitate induces MMP-9 and CCL4 expression in the human monocytic cells via TLR4/MyD88 signaling $[8,15]$. However, it remains to be seen whether palmitate can induce the induction of MIP- $1 \alpha$ in human monocytic cells. Herein, we present the data showing that palmitate induces MIP-1 $\alpha$ expression in monocytes/macrophages through the mechanism involving TLR4/MyD88/NF-kB/AP-1 axis. Besides, this TLR4-mediated MIP-1 $\alpha$ production also implicates the PI3 kinase activity. 


\section{Cellular Physiology Cell Physiol Biochem 2019;52:212-224

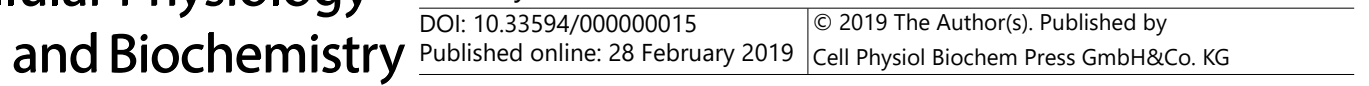 \\ Ahmad et al:: MIP-1 $\alpha$ Induction by Palmitate}

\section{Materials and Methods}

\section{Cell Culture}

Human monocytic leukemia cell line THP-1 was purchased from American Type Culture Collection (ATCC) and propagated in RPMI-1640 culture medium (Gibco, Life Technologies, Grand Island, USA) containing 10\% fetal bovine serum (FBS; Gibco, Life Technologies, Grand Island, NY, USA), 2 mM glutamine (Gibco, Invitrogen, Grand Island, NY, USA), $1 \mathrm{mM}$ sodium pyruvate, $10 \mathrm{mM}$ HEPES, $100 \mu \mathrm{g} / \mathrm{mL}$ Normocin, 50 $\mathrm{U} / \mathrm{mL}$ penicillin and $50 \mu \mathrm{g} / \mathrm{mL}$ streptomycin (Gibco, Invitrogen, Grand Island, NY, USA). Cells were incubated in a humidified incubator at $37^{\circ} \mathrm{C}$ and $5 \% \mathrm{CO}_{2}$. THP-1-XBlue cells stably expressing a secreted embryonic alkaline phosphatase (SEAP) reporter inducible by NF- $\kappa$ B and AP-1 as well as THP-1-XBlue ${ }^{\mathrm{TM}}$-defMyD cells (cells deficient in MyD88 activity or MyD88-/- THP-1 cells) were purchased from InvivoGen (InvivoGen, San Diego, CA, USA). THP-1-XBlue cells were cultured in complete RPMI medium containing $200 \mu \mathrm{g} / \mathrm{mL}$ zeocin (InvivoGen, San Diego, CA, USA) to select cells expressing SEAP-NF- $\kappa$ B/AP-1 reporter. THP-1-XBlue ${ }^{\mathrm{TM}}$-defMyD cells were cultured in complete RPMI medium supplemented with Zeocin $(200 \mu \mathrm{g} / \mathrm{mL})$ and HygroGold $(100$ $\mu \mathrm{g} / \mathrm{mL}$; InvivoGen, San Diego, CA, USA). Before stimulation, THP-1 cells were transferred to normal medium and plated at a cell density of $1 \times 10^{6}$ cells/well in 12-well plates (Costar, Corning Incorporated, Corning, NY, USA) unless otherwise indicated.

\section{Stimulation of THP-1 monocytic cells and THP-1-derived macrophages}

THP-1 monocytic cells were plated at a cell density of $1 \times 10^{6}$ cells/well in 12 -well plates. Cells were stimulated with $100 \mu \mathrm{M}$ palmitate (Sigma, San Diego, CA, USA) or $10 \mathrm{ng} / \mathrm{mL}$ LPS (Sigma, Saint Louis, MO, USA) or $0.1 \%$ BSA or TNF- $\alpha$ and incubated at $37^{\circ} \mathrm{C}$ for $24 \mathrm{~h}$. Cells were collected by centrifugation for total RNA isolation and culture media were aliquoted for determining MIP- $1 \alpha$ protein concentrations. For preparing THP-1 cell-derived macrophages, cells $\left(1 \times 10^{6}\right.$ cells $\left./ \mathrm{mL}\right)$ plated in 12 well plates were treated with PMA (50 ng/mL) and incubated at $37^{\circ} \mathrm{C}$ for $72 \mathrm{~h}$. Differentiated macrophages were stimulated with palmitate $(100 \mu \mathrm{M})$ or TNF- $\alpha(10 \mathrm{ng} / \mathrm{mL})$ or $0.1 \%$ BSA and incubated at $37^{\circ} \mathrm{C}$ for $24 \mathrm{~h}$. Cells were harvested for total RNA isolation and culture media were aliquoted and stored at $-80^{\circ} \mathrm{C}$ until use for determining MIP$1 \alpha$ concentrations.

\section{Intracellular Staining and Flow Cytometry}

THP-1 cells were incubated with BSA (vehicle), palmitate or TNF- $\alpha$ for 4 hrs and then brefeldin A was added. After $24 \mathrm{hrs}$ incubation, cells were harvested. Intracellular staining for MIP-1 $\alpha$ was conducted by incubating cells in a fixation/permeabilization solution (cat\# 00-5523-00, eBioscience, San Diego, CA, USA). Following fixation and permeabilization, the cells were incubated with mouse anti-human MIP- $1 \alpha$ antibody (cat \# 554730, BD Biosciences) for 40 mins. The cells were then washed with permeabilization buffer and resuspended in PBS supplemented with $2 \%$ formalin for FACS analysis (FACSCanto II; BD Bioscience, San Jose, USA). FACS data analysis was performed using BD FACSDivaTM Software 8 (BD Biosciences, San Jose, USA)

\section{Small interfering RNA (siRNA) transfections}

Aliquots of THP-1 cells were washed and resuspended in nucleofector solution $(100 \mu \mathrm{L}$ each) (Amaxa Nucleofector Kit V, Lonza, Germany) and transfected separately with TLR4 siRNA (30nM; OriGene Technologies, Inc. MD, USA), scramble (control) siRNA (30nM; OriGene Technologies, Inc. MD, USA, USA) and pmaxGFP (0.5 $\mu \mathrm{g}$; Amaxa Nucleofector Kit V for THP-1 cells, Lonza, Germany). Transfection efficiency was analyzed by fluorescence microscopy and TLR4 gene knock down was assessed by real time RT-PCR using TLR4 gene specific primer probes. All transfection experiments were performed using Amaxa Cell Line Nucleofector Kit V for THP-1 (Lonza, Germany) and Amaxa Electroporation System (Lonza, Germany), following the manufacturer's instructions. After $36 \mathrm{~h}$ of transfection, cells were treated with $100 \mu \mathrm{M}$ palmitate and incubated at $37^{\circ} \mathrm{C}$ for $24 \mathrm{~h}$. 


\section{Cellular Physiology Cell Physiol Biochem 2019;52:212-224 \\ \begin{tabular}{l|l|l}
\hline DOI: 10.33594/000000015 & ( 2019 The Author(s). Published by
\end{tabular} \\ \begin{tabular}{l|l} 
Published online: 28 February 2019 & Cell Physiol Biochem Press GmbH\&Co. KG \\
\hline
\end{tabular} \\ Ahmad et al.: MIP- $1 \alpha$ Induction by Palmitate}

\section{Real Time RT-PCR}

Total cellular RNA was isolated using RNeasy Mini Kit (Qiagen, Valencia. CA, USA) and cDNA was synthesized using $1 \mu \mathrm{g}$ of total RNA sample (High capacity cDNA reverse transcription kit; Applied Biosystems, Foster city, CA, USA). For real time PCR, 50 ng of each cDNA sample was amplified using Inventoried TaqMan Gene Expression Assay products including MIP-1 $\alpha$ : Hs00234142_m1; GAPDH: Hs03929097_g1; and TLR-4: Hs00152939_m1 containing two gene-specific primers and one TaqMan MGB probe (6-FAM dye-labeled) using a TaqMan® Gene Expression Master Mix (Applied Biosystems, Foster city, CA, USA) in 7500 Fast RealTime PCR System (Applied Biosystems, Foster City, CA, USA). Target mRNA levels were normalized against GAPDH mRNA and MIP-1 $\alpha$ gene expression relative to control was calculated using $2^{-\Delta \Delta C T}$ method. Relative mRNA expression was expressed as fold expression over average of control gene expression.

\section{MIP-1 $\alpha$ measurement by ELISA}

Secreted MIP-1 $\alpha$ protein was measured by sandwich ELISA in cell supernatants following the manufacturer's instructions (R\&D systems, Minneapolis, USA).

\section{$N F-\kappa B / A P-1$ activity measurement}

In this assay, we used THP-1-XBlue cells that were stably transfected with SEAP reporter construct regulated and expressed by $\mathrm{NF}-\kappa \mathrm{B} / \mathrm{AP}-1$ inducible promoter. NF- $\mathrm{KB} / \mathrm{AP}-1$ are activated following cell stimulation and SEAP expression is measured accordingly. THP-1-XBlue cells were stimulated with palmitate $(100 \mu \mathrm{M})$ or TNF- $\alpha\left(10 \mathrm{ng} / \mathrm{mL}\right.$; positive control) and incubated at $37^{\circ} \mathrm{C}$ for $24 \mathrm{~h}$. SEAP levels were measured in the culture media after incubating supernatants with Quanti-Blue solution (InvivoGen, San Diego, CA, USA) for $3 \mathrm{~h}$ and optical density was measured using ELISA reader at $650 \mathrm{~nm}$ wave length.

\section{Western blotting}

Cellular lysates were prepared, and protein was resolved on SDS-12\% SDS-PAGE as described previously $(8,15)$. The blots were probed with rabbit anti-human antibodies against p-NF-kB and total NF$\mathrm{kB}$ in 1:1000 dilution at $4^{\circ} \mathrm{C}$ overnight. All the primary antibodies were purchased from Cell Signalling (Cell Signalling Technology, Inc). The blots were then washed three times with TBS and incubated for $2 \mathrm{~h}$ with HRP-conjugated secondary antibody (Promega, Madison, WI, USA). Immunoreactive bands were developed using an Amersham ECL Plus Western Blotting Detection System (GE Health Care, Buckinghamshire, UK) and visualized by Molecular Imager $\AA$ VersaDoc ${ }^{\text {TM }}$ MP Imaging Systems (Bio-Rad Laboratories, Hercules, CA, USA).

\section{Statistical analysis}

GraphPad Prism software (La Jolla, CA, USA) was used for statistical analysis of data obtained. All data are shown as mean \pm SEM unless otherwise stated. Unpaired Student's t-test was used to compare group means. All P-values $<0.05$ were considered significant.

\section{Results}

Palmitate upregulates MIP-1 $\alpha$ expression in the human monocytes/macrophages

Given that increased palmitate and MIP- $1 \alpha$ levels have been reported in obesity/T2D [16], we assessed whether the human monocytic THP-1 cells treatment with palmitate could upregulate MIP-1 $\alpha$ expression. Treatment of THP-1 cells with palmitate resulted in significantly increased MIP-1 $\alpha$ mRNA expression compared to BSA (vehicle) treated cells (8.18 \pm 0.54-fold, $\mathrm{P}=0.0029$ ) (Fig. 1A). As expected, MIP-1 $\alpha$ protein concentration in the supernatant of palmitate treated cells also increased $(344 \pm 20 \mathrm{pg} / \mathrm{mL}, \mathrm{P}=0.001)$ (Fig. 1B). Similarly flow cytometry staining data (Fig. 1C and D) data revealed that MIP-1 $\alpha$ was highly expressed in THP-1 cells treated with palmitate when compared to cells treated with vehicle (Fig. 1C-F). Because of the direct functional implication of macrophages in metabolic inflammation, we next asked whether palmitate exposure could induce MIP-1 $\alpha$ gene expression in the macrophages as well. A similar pattern of MIP-1 $\alpha$ expression was observed for palmitate stimulated THP-1 cells derived macrophages (Fig. 2A and B). 


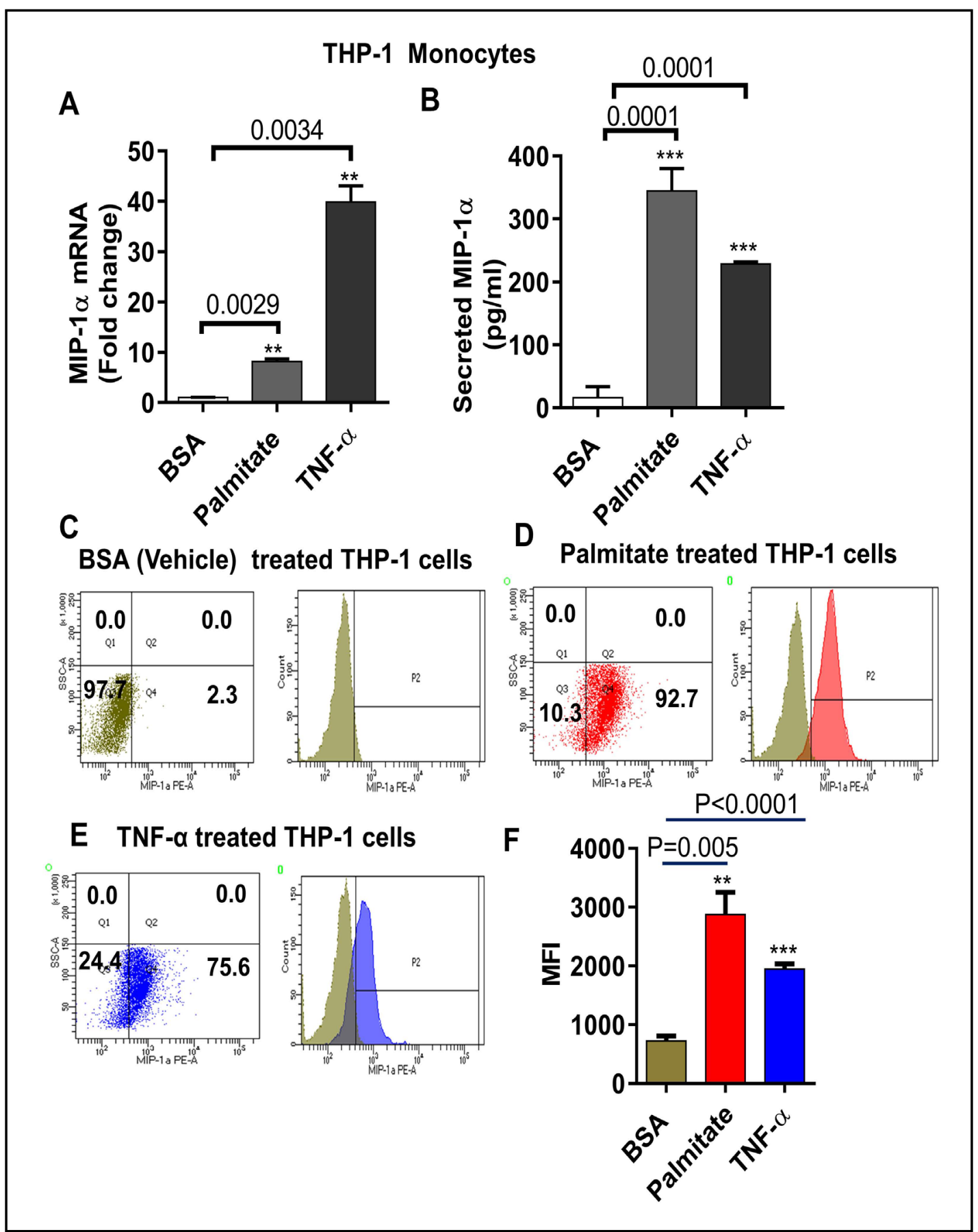

Fig. 1. Effect of palmitate on MIP-1 $\alpha$ production in human monocytic cells. THP-1 cells were incubated with $0.1 \%$ BSA (vehicle) palmitate $(100 \mathrm{uM})$, TNF-a $(10 \mathrm{ng} / \mathrm{ml}$; a positive control) for $24 \mathrm{hrs}$. Cells and culture media were collected. RNA was isolated and MIP- $1 \alpha$ mRNA was quantified by real time PCR (A). MIP- $1 \alpha$ protein in culture media was determined by ELISA (B). Analysis of MIP- $1 \alpha$ expression using intracellular flow cytometry. Flow cytometry data are presented in flow dots plot (left) and histogram (right) (C-E). Bar graphs depict mean values \pm SEM of fluorescence intensity (MFI) for MIP-1 $\alpha$ (F). Data are represented as mean \pm SEM. Statistical analysis was done using t-test. $\mathrm{P}<0.05$ was considered as statistically significant ${ }^{*}$ $\left.\mathrm{P}<0.01 ;{ }^{* *} \mathrm{P}<0.001,{ }^{* * *} \mathrm{P}<0.0001\right)$. The data in all Fig.s are representative of three independent experiments. 
Palmitate mediated production of MIP- $1 \alpha$ is dependent on TLR4

Since the TLR4 has been associated with the production of some cytokines in response to free fatty acids $[8,17]$, we hypothesized that TLR4 was involved in the up-regulation of MIP-1 $\alpha$ gene expression in human monocytic cells after incubation with palmitate. This was accomplished by exposing both monocytes and macrophages to an anti-TLR4-neutralizing monoclonal antibody or an isotype control antibody prior to the treatment with palmitate. Neutralization of TLR4 with an anti-TLR4 mAb led to significant inhibition of palmitateinduced MIP-1 $\alpha$ expression in both monocytes (Fig. 3A and B) and macrophages (3C and D). There was no change observed in the expression of MIP- $1 \alpha$ in cells treated with the isotype control antibody. Moreover, TLR4 gene suppression in THP-1 cells was also achieved by TLR4 siRNA transfection (Fig. 3E). Again, palmitate-induced MIP-1 $\alpha$ gene/protein expression was found to be significantly suppressed $(\mathrm{P}<0.05)$ in TLR4 siRNA-transfected cells as compared to scramble siRNA-transfected controls (Fig. 3F and G). Since LPS is a known ligand for TLR4 and its elevated levels have been observed in obese rodents and humans, we asked whether the LPS also induced MIP- $1 \alpha$. Our results showed that LPS induces the production of MIP- $1 \alpha$ in monocytic cells (Fig. $3 \mathrm{H}$ and I). Altogether, these results demonstrate the requirement of the TLR4-mediated signaling for upregulated expression of MIP-1 $\alpha$ in monocytic cells.

\section{Palmitate -induced MIP-1 $\alpha$ up-regulation in THP-1 cells is MyD88-dependent}

TLR4-mediated signaling may or may not be MyD88-dependent [18]. Therefore, we asked if the palmitate-induced MIP- $1 \alpha$ expression in THP-1 monocytic cells required MyD88 adaptor protein. To this end, we treated MyD88-KO monocytic cells with palmitate or TNF- $\alpha$ (used as positive control). Our data show that the palmitate-induced MIP-1 $\alpha$ expression was significantly abrogated in MyD88-deficient cells at both mRNA and protein levels whereas, the TNF- $\alpha$-induced MIP-1 $\alpha$ expression remained unchanged since it involves signaling through the MyD88-independent pathway (Fig. 4A and B). As expected, LPS did not induce MIP-1 $\alpha$ in MyD88 KO cells. These data further support that palmitate-induced MIP-1 $\alpha$ expression in THP-1 monocytic cells was TLR signaling pathway dependent.

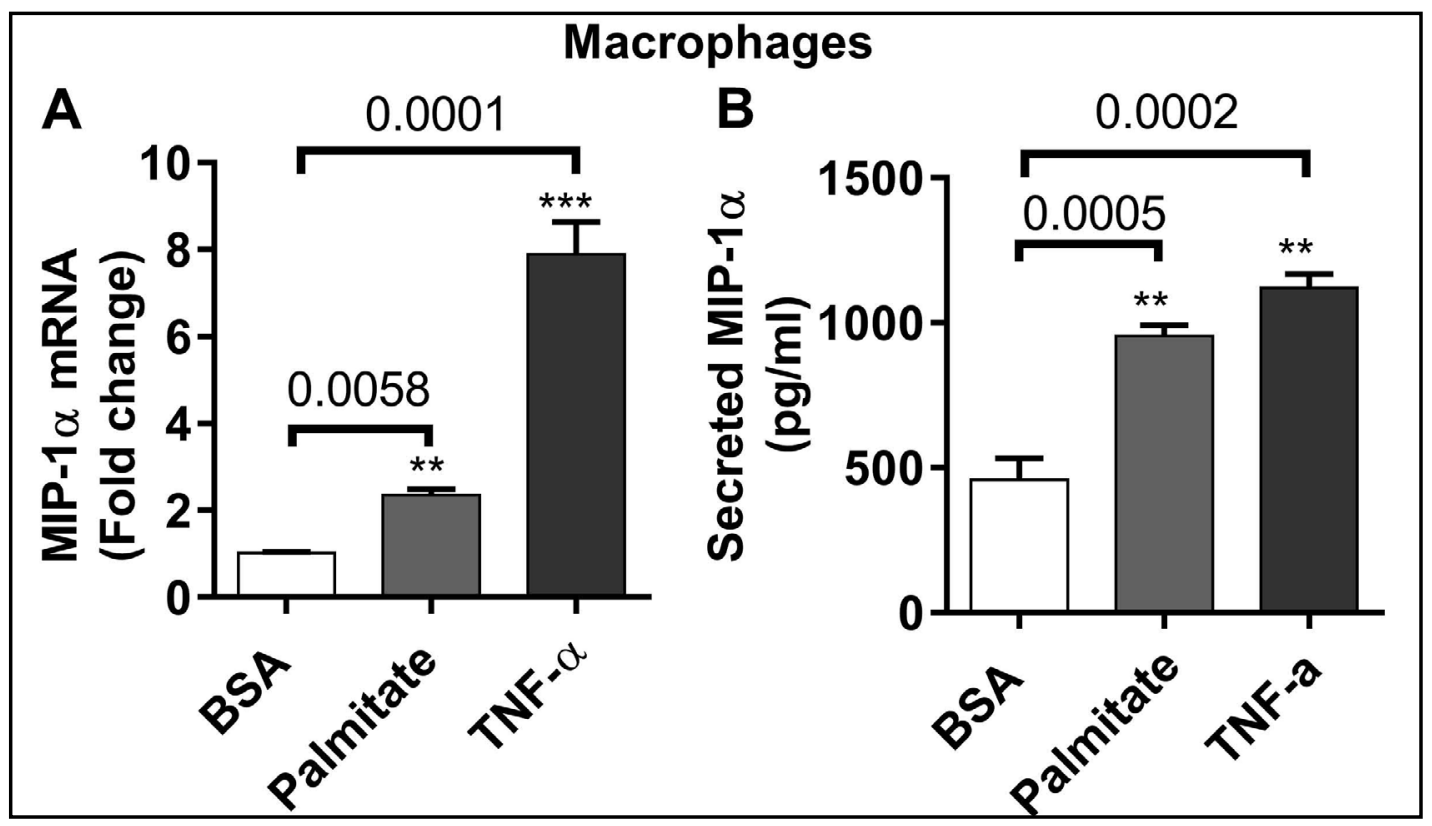

Fig. 2. Effect of palmitate on MIP-1 $\alpha$ production in macrophages. THP-1 cells derived macrophages were treated with palmitate, TNF- $\alpha$ or BSA for $24 \mathrm{hrs}$. Cells and culture media were collected. RNA was isolated and MIP- $1 \alpha$ mRNA was quantified by real time PCR (A). MIP- $1 \alpha$ protein in culture media was determined by ELISA (B). Data are represented as mean \pm SEM. Statistical analysis was done using t-test. $\mathrm{P}<0.05$ was considered as statistically significant $\left({ }^{*} \mathrm{P}<0.01 ;{ }^{*} \mathrm{P}<0.001,{ }^{* * *} \mathrm{P}<0.0001\right)$. 

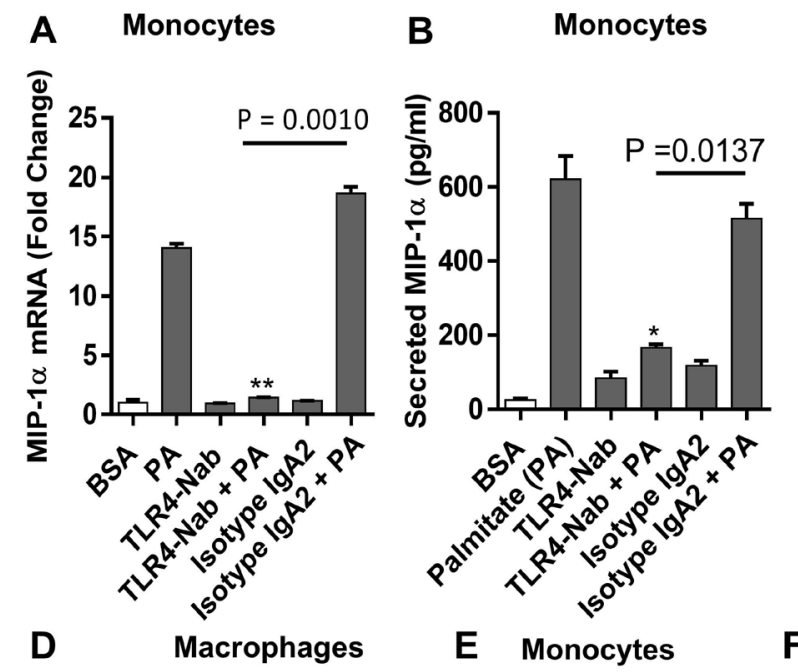

\section{Macrophages}
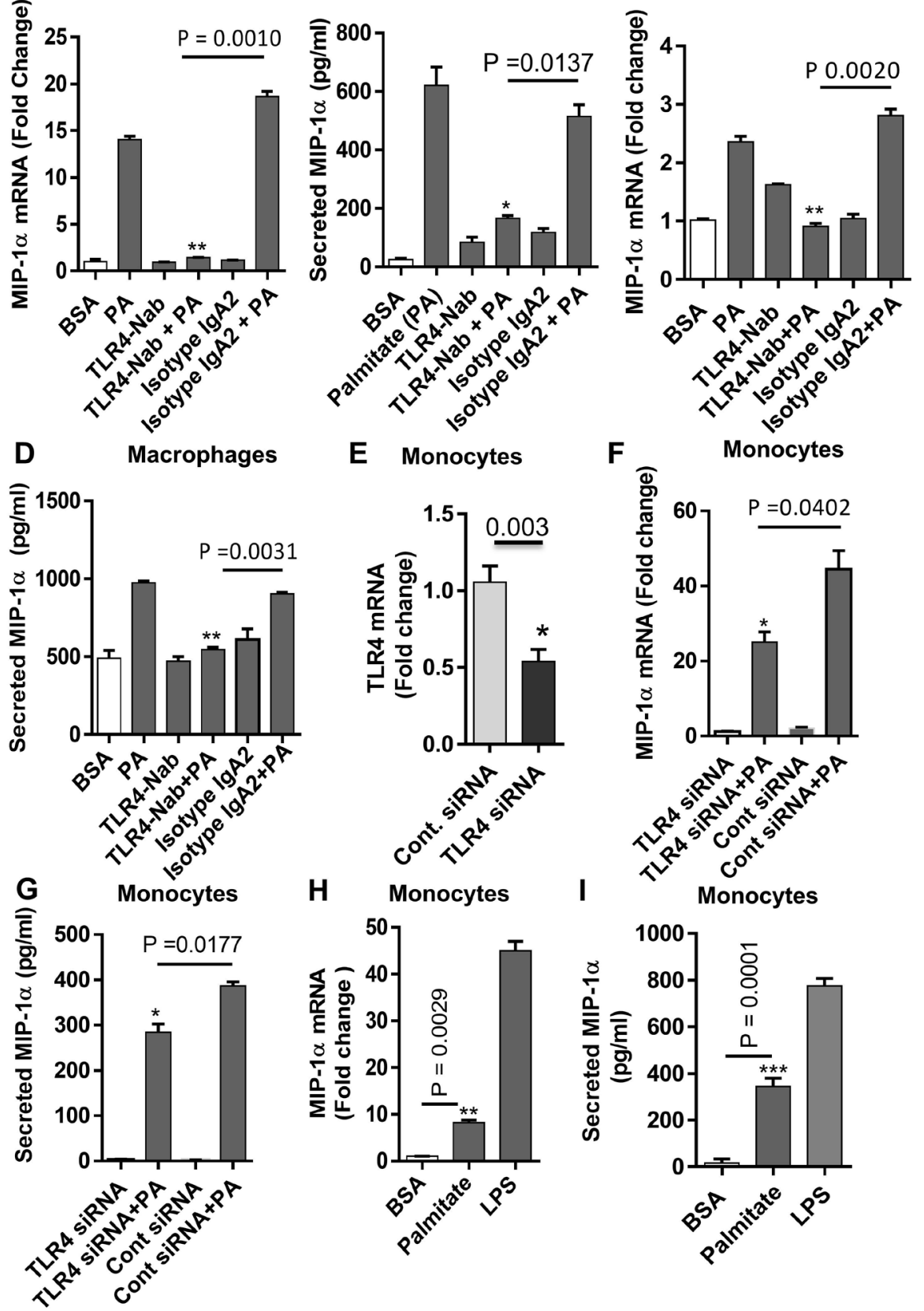

Fig. 3. Inhibition of TLR4 down-regulates the palmitate induced MIP-1 $\alpha$. Anti-TLR4 antibody or isotypematched control antibody (IgA) treated THP-1 cells were incubated with $0.1 \%$ BSA (vehicle) or palmitate $(100 \mu \mathrm{M})$ for $24 \mathrm{hrs}$. Cells and culture media were collected. MIP-1 $\alpha$ mRNA and protein were determined (A and B). THP-1 derived macrophages were treated with TLR4 and control antibody and treated as indicated. MIP-1 $\alpha$ mRNA and protein were determined (C and D). THP-1 cells were transfected with either control siRNA (30nM) or siRNA (30nM) against TLR4 (E). Cell were treated as indicated and MIP-1 $\alpha$ expression was determined (F and G). THP-1 cells were incubated with $0.1 \%$ BSA (vehicle) palmitate $(100 \mu \mathrm{M})$, LPS $(10$ $\mathrm{ng} / \mathrm{ml}$; a positive control for TLR4 activation) for $24 \mathrm{hrs}$. Cells and culture media were collected. MIP-1 $\alpha$ expression was determined ( $\mathrm{H}$ and $\mathrm{I}$ ). The data are presented as mean \pm SEM. Statistical analysis was done using t-test. $\mathrm{P}<0.05$ was considered as statistically significant $\left({ }^{*} \mathrm{P}<0.05 ;{ }^{* *} \mathrm{P}<0.005\right)$. 


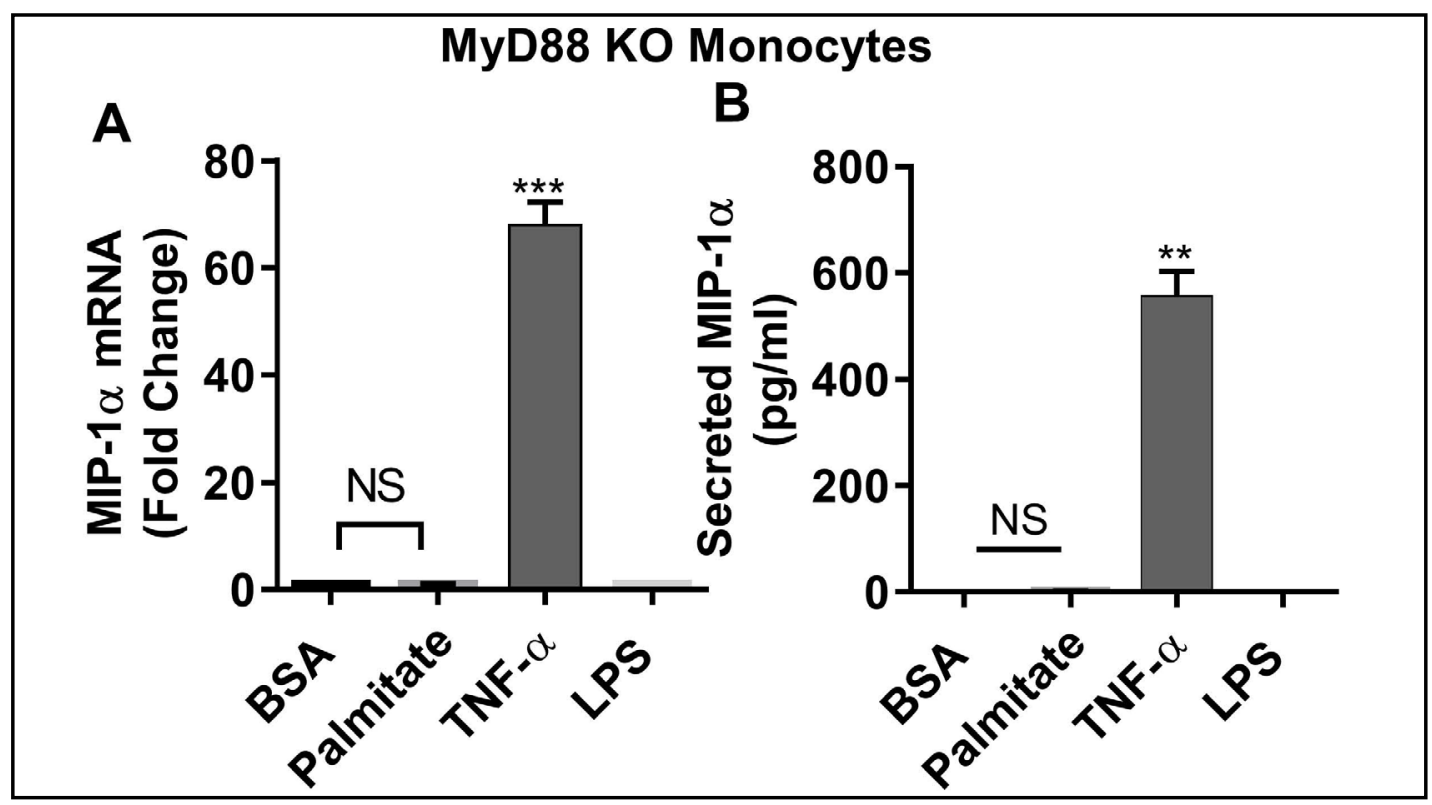

Fig. 4. MyD88 deficiency reduced the palmitate induced expression of MIP-1 $\alpha$. MyD88 KO human monocytic cells were incubated with $0.1 \%$ BSA (Vehicle) or palmitate $(100 \mu \mathrm{m})$ or TNF- $\alpha(10 \mathrm{ng} / \mathrm{ml}$; MyD88 independent stimulus) or LPS (10ng/ml; TLR4/MyD88 dependent stimulus). Cells and culture media were collected after $24 \mathrm{hrs}$. MIP-1 $\alpha$ gene expression was determined by real time PCR (A) and secreted MIP- $1 \alpha$ protein was determined in culture media by ELISA (B). The data are presented as mean \pm SEM. Statistical analysis was done using t-test. $\mathrm{P}<0.05$ was considered as statistically significant. ${ }^{* *} \mathrm{P}<0.001$.

MAPK, NF- $K B / A P-1$ and PI3K/AKT signaling pathways are involved in palmitate induced $M I P-1 \alpha$ expression in monocytic cells

MAPK and NF-kB signaling pathways are known to be activated downstream of TLR/ ligand interaction $[8,10]$. We next asked whether the MAPK and NF- $\kappa B$ signaling pathways were involved in palmitate-induced MIP- $1 \alpha$ expression in monocytic cells. Therefore, we analyzed the effects of MAPK pathway inhibition on palmitate-stimulated MIP- $1 \alpha$ expression in these cells. As shown in Fig. 5A and B treatment of cells with the mitogen-activated ERK kinase 1/2 (MEK1/2)-ERK1/2 signaling inhibitor (PD98059), c-Jun N-terminal kinase $1 / 2(J N K 1 / 2)$ inhibitor (SP600125), or the p38 MAPK inhibitor (SB203580) significantly attenuated the palmitate-stimulated MIP- $1 \alpha$ expression in THP-1 cells. Likewise, NF-kB signaling pathways inhibitors (NDGA, Bay 11-7085, Triptolide) also decreased the palmitate induced production by monocytes (Fig. 5C and D). Since it has been reported that PI3-kinase signaling pathway is an important mediator of LPS and IL-1 $\beta$ signaling, leading to the NF$\kappa B$ activation in endothelial cells, we asked whether the inhibition of PI3 Kinase/AKT could suppress the palmitate mediated production of MIP- $1 \alpha$. To this end, cells treated with PI3 Kinase/AKT pathway inhibitors (wortmannin; LY294002) showed significantly reduced the production of MIP-1 $\alpha$ when incubated with Palmitate (Fig. 5E and F).

NF-kB and AP-1 activation is known to be involved in gene transcription of many inflammatory genes in response to TLR4 signaling. Next, we asked whether NF-kB and AP-1 was activated in response to palmitate while induction of MIP- $1 \alpha$ in monocytic cells. Our data show that palmitate induced the NF- $\mathrm{KB} / \mathrm{AP}-1$ activity together with MIP- $1 \alpha$ expression in the cells transfected with a SEAP reporter (Fig. 6A and B). Likewise, LPS also induced the activation of NF-kB/AP-1. Furthermore, NF-kB/AP-1 activation was not observed in the MyD88 deficient monocytic cells following exposure to palmitate or LPS (Fig. 6C and D). Our data also show that THP-1 cells stimulation with palmitate increased NF-kB phosphorylation (Fig. 6E). 


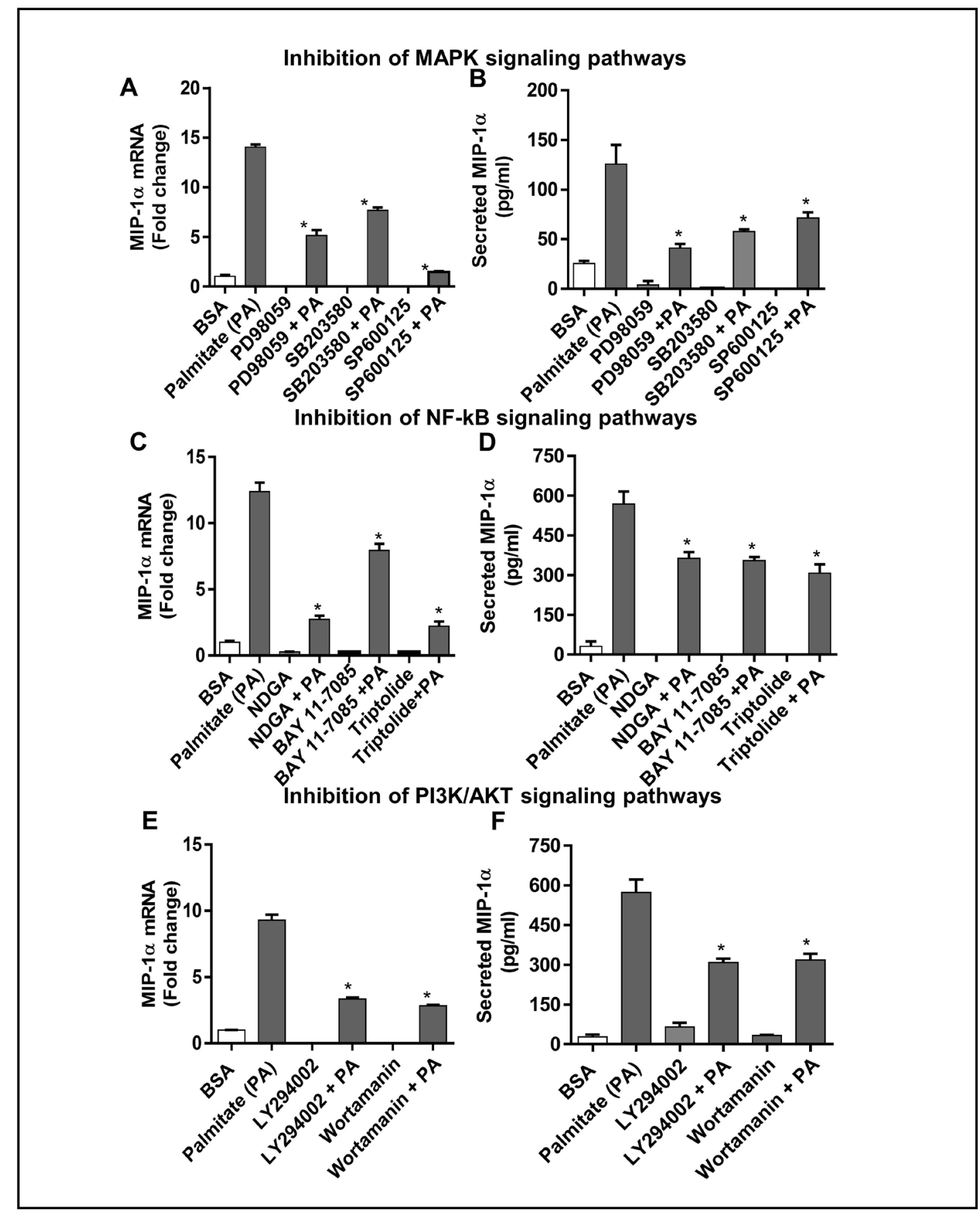

Fig. 5. Inhibition of MAPK, NF- $\kappa B$ and PI3K/Akt signaling pathways suppressed palmitate induced MIP$1 \alpha$ production. THP-1 cells were pretreated with MEK-ERK inhibitors (PD98059: 10 $\mu \mathrm{M}$ ) or p38 MAPK inhibitor (SB203580) or JNK inhibitor (SP600125: 20 $\mu \mathrm{M}$ ) for $1 \mathrm{hr}$ and then incubated with palmitate for 24 hrs. Cells and supernatants were collected. MIP- $1 \alpha$ mRNA and protein were determined by real time RT-PCR and ELISA, respectively (A and B). Cells were pretreated with NF-kB signaling pathways inhibitors (NDGA: $10 \mu \mathrm{M}$, Bay 11-7085:10 $\mu \mathrm{M}$, Triptolide: $5 \mu \mathrm{M}$ ) and then incubated with palmitate as indicated. MIP-1 $\alpha$ mRNA and protein were determined (C and D). Cells were pretreated with PI3 Kinase/AKT pathway inhibitors (LY294002: 50 $\mu \mathrm{M}$; Wortmannin: 100nM) for $1 \mathrm{hr}$ and then incubated with palmitate. MIP-1 $\alpha$ mRNA and protein were determined ( $\mathrm{E}$ and $\mathrm{F}$ ). The results obtained from three independent experiments are shown. The data are presented as mean \pm SEM. Statistical analysis was done using t-test. $\mathrm{P}<0.05$ was considered as statistically significant. ${ }^{*} \mathrm{P}<0.05$. 
Fig. 6. NF-kB/AP-1 activation is associated with palmitate induced MIP- $1 \alpha$ production. NF-KB and AP-1 reporter monocytic cells were treated with $0.1 \%$ BSA (vehicle) palmitate $(100 \mu \mathrm{M})$ or TNF- $\alpha(10 \mathrm{ng} / \mathrm{ml})$ or LPS (ligand for TLR4; $10 \mathrm{ng} / \mathrm{ml}$ ) for $24 \mathrm{hrs}$. Culture media were collected. Cell culture media were assayed for SEAP reporter activity (degree of NF- $\mathrm{kB} /$ AP-1 activation) along with MIP- $1 \alpha$ protein production (A and B). NF-kB/AP-1 reporter MyD88 KO human monocytic cells were treated with $0.1 \%$ BSA or palmitate or TNF- $\alpha$ or LPS for 24 hrs. SEAP reporter activity (degree of NF$\kappa B / A P-1$ activation) along with the secreted MIP- $1 \alpha$ protein was determined in the cell culture media (C and D). THP-1 cells were treated with palmitate for different time points and cell lysates were prepared as described in methods. Samples were run on denaturing gels. Phosphorylated NF-kB is shown in the upper panel and total respective protein is shown in the lower panel (E). The results obtained from three independent experiments are shown. The data are presented as mean \pm SEM. Statistical analysis was done using t-test. $\mathrm{P}<0.05$ was considered as statistically significant. ${ }^{* *} \mathrm{P}<$ $0.001,{ }^{* * *} \mathrm{P}<0.0001$.

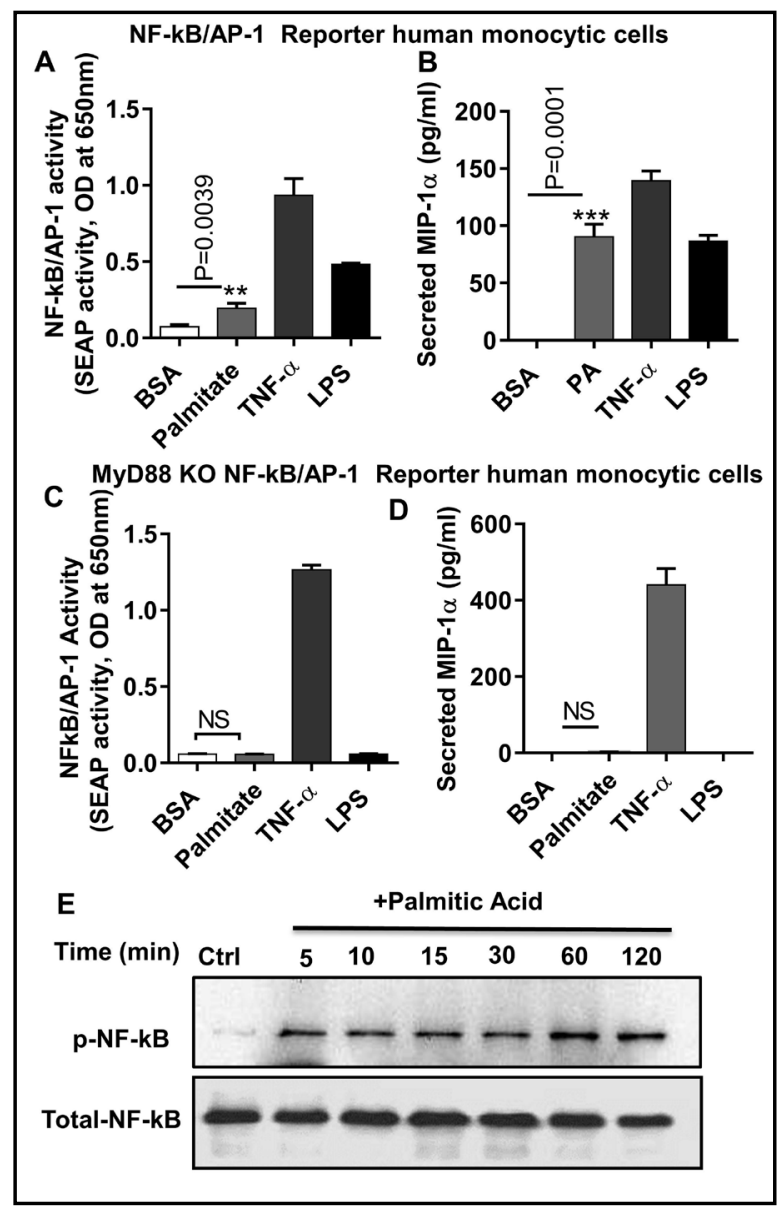

\section{Discussion}

Palmitate and MIP-1 $\alpha$ may be cooperatively linked for fueling metabolic inflammation since their increased levels have been documented in obesity $[6,16,19]$. Chemokines, including MIP-1 $\alpha$, enhance the metabolic inflammation by regulating monocytes migration into the adipose tissue [20]. The free fatty acids are elevated in obesity and are involved in the activation of inflammatory pathways in immune cells, adipocytes, and primary microvascular endothelial cells as well as impair insulin transport and enhance monocyte transmigration $[6,21]$. This study reports the palmitate-induced MIP- $1 \alpha$ expression in human monocytic cells/macrophages. The data show the increased expression of MIP-1 $\alpha$ mRNA and protein in THP-1 monocytic cells and THP-1-derived macrophages through the mechanism that involves TLR4/MyD88-dependent signaling.

We and others have previously shown the altered TLRs' expression in obesity [22, 23]. TLRs are emerging as the nutrient sensors and coplayers in metabolic inflammation, especially, the TLR4 has been identified as a main cognate receptor for FFAs. Saturated fatty acids were reported to activate the TLR4 signaling pathway in macrophages [8, 24, 25]. In this regard, we and others have reported that palmitate activation of monocytes/macrophages involved the TLR4-mediated signaling and resulted in the production of key inflammatory mediators $[8,25]$. TLR4 expression in the cells of monocytic lineage is well known; however, we found that TLR4-mediated palmitate activation of the human monocytes/macrophages upregulated MIP- $1 \alpha$ expression in these cells. In further consolidating the involvement of TLR4 in this phenomenon, our data show that interrupting the TLR4 signaling either by 


\section{Cellular Physiology \\ \begin{tabular}{ll|l} 
and Biochemistry Published online: 28 February 2019 & C 2019 The Author(s). Published by \\
Cell Physiol Biochem Press GmbH\&Co. KG
\end{tabular} \\ Ahmad et al.: MIP- $1 \alpha$ Induction by Palmitate}

specific neutralizing antibody or by TLR4 siRNA significantly abrogated the palmitateinduced MIP-1 $\alpha$ expression in monocytic cells. We also examined the effect of LPS on MIP-1 $\alpha$, since LPS is a strong activator of innate immune TLR4 signaling and is found to be elevated in the state of obesity. LPS showed the similar impact as of palmitate on the induction of MIP$1 \alpha$ in monocytic cells.

Following ligand binding, TLRs recruit the TIR domain-containing adaptor proteins, MyD88 and TRIF, to initiate the signal transduction involving NF- $\kappa B$ and MAPKs. We also found that palmitate-induced MIP-1 $\alpha$ expression in monocytic cells was MyD88-dependent. NF- $\kappa \mathrm{B}$ and MAPKs are the classical, TLR-downstream signaling molecules and we showed previously that TLR -stimulation of monocytic cells promoted phosphorylation of the ERK $1 / 2$, JNK and NF- $\mathrm{BB}$ [8-10]. Our results indicate that the inhibition of MAPKs significantly downmodulated the MIP- $1 \alpha$ induction by palmitate in monocytic cells. ERK $1 / 2$ and JNK can be activated by different stimuli in different cell types [26]. The present data also indicate that the inhibition of the NF- $\kappa$ B pathway largely suppressed MIP- $1 \alpha$ production. These findings corroborate our previous reports showing activation of MAPKs, except p38 MAPK, regarding MMP-9 expression by human monocytic cells. Also, MMP-9 expression was abrogated when NF- $\kappa B$ pathway was inhibited $[8,9]$. Our data show that palmitate stimulation enhances NF$\kappa B / A P-1$ signaling. In agreement with this, LPS stimulation was found to activate the TLR4/ NF- $\kappa \mathrm{B} / \mathrm{AP}-1$ signaling for cytokines/chemokines expression [27]. NF- $\kappa \mathrm{B}$ was involved, at least in part, in IL-1 $\beta$-mediated expression of MIP-1 $\alpha$ in human neuronal cells [28]. LPS signaling via TLR4/MyD88 activates the AKT/PI3K in endothelial cells. AKT kinase is a key downstream target of PI3K and MyD88-defective cells did not show AKT kinase activity in response to LPS stimulation [29]. Interestingly, we show here that AKT/PI3K inhibition abrogated the palmitate-induced MIP-1 $\alpha$ expression in human monocytes. TLR4-mediated cytokine expression in macrophages was partly related to PI3K activation [30]. These data overall support that palmitate-induced, TLR4/MyD88-dependent MIP-1 $\alpha$ expression involves activation of the AKT/PI3K signaling in monocytic cells.

Increasing evidence supports that circulatory levels of saturated free fatty palmitate are increased significantly in obesity. We and others have reported contribution of palmitate in promoting expression of various proinflammatory cytokines/chemokines that are considered hallmark of obesity and/or T2D $[12,17,31]$. The present data support the role of palmitate in promoting expression of proinflammatory MIP- $1 \alpha$ in monocytes/macrophages. Adipose tissue macrophages actively secrete a wide range of proinflammatory cytokines/ chemokines that may also play a role engaging in crosstalk with adipocytes and lead to adipokine secretion. These inflammatory cytokines/adipokines directly contribute to initiate a chronic low-grade inflammatory response within the adipose tissue in obesity. It is noteworthy that the human diets containing fats from animal origin or a plant source like palm oil would be rich in palmitic acid content and, therefore, a degree of caution will be required while consuming palmitate-rich processed foods since emerging data support the palmitate role as a positive modulator of inflammation.

\section{Conclusion}

Our findings suggest that saturated fatty acid palmitate induces the MIP- $1 \alpha$ expression in monocytes/macrophages via the TLR4/MyD88-dependent activation of NF-kB/MAP Kinases and AKT/PI3 Kinases which may have potential immunobiological significance in metabolic inflammation. 


\section{Cellular Physiology Cell Physiol Biochem 2019;52:212-224 \begin{tabular}{ll|l} 
and Biochemistry & $\begin{array}{l}\text { DOl: 10.33594/000000015 } \\
\text { Published online: } 28 \text { February } 2019\end{array}$ & $\begin{array}{l}\text { C 2019 The Author(s). Published by } \\
\text { Cell Physiol Biochem Press GmbH\&Co. KG }\end{array}$ \\
\cline { 2 - 3 }
\end{tabular} \\ Ahmad et al.: MIP-1 $\alpha$ Induction by Palmitate}

\section{Abbreviations}

AP-1 (Activator protein); ATCC (American Type Culture Collection); ATMs (Adipose tissue macrophages); BSA (Bovine Serum Albumin); CCL3 (Chemokine (C-C motif) ligand 3); CCL4 (Chemokine (C-C motif) ligand 4); ECM (Extracellular matrix); ELISA (Enzymelinked immunosorbent assay); FFA (Free fatty acid); GAPDH (Glyceraldehyde-3-phosphate dehydrogenase); LPS (Lipopolysaccharide); MAPK (Mitogen-activated protein kinase); MIP-1 (macrophage inflammatory protein); MMP-9 (Matrix metalloproteinase-9); MyD88 (Myeloid differentiation factor 88); NF- $\mathrm{BB}$ (Nuclear factor-kappaB); PA (Palmitate (palmitic acid)); PAMPs (Pathogen-associated molecular patterns); PBMC (Peripheral blood mononuclear cells); PVDF (Polyvinylidene difluoride membrane); SFA (Saturated fatty acid); SEAP (Secreted embryonic alkaline phosphatase); THP-1 (A human monocytic cell line); TIR (Interleukin (IL)-1 receptor called toll-IL1-R); TLRs (Toll-like receptors); TNF- $\alpha$ (Tumor necrosis factor-alpha); TRAM (TRIF-related adaptor molecule); TRIF (TIR-domaincontaining adapter-inducing IFN- $\beta$ ).

\section{Acknowledgements}

This study was financially supported by Kuwait Foundation for the Advancement of Sciences (KFAS). Grants \#: RA AM 2016-007; RA-AM-2017-007). NA, SK, AW, AA and RT and SS participated in performing experiments and analyzing the data. Sardar S participated in writing paper. JT critically reviewed manuscript. RA conceived the idea, supervised research, designed experiments, analyzed the data, and wrote the manuscript.

\section{Disclosure Statement}

The authors declare that they have no competing interests.

\section{References}

- 1 Moller DE, Kaufman KD: Metabolic syndrome: A clinical and molecular perspective. Annu Rev Med 2005;56:45-62.

2 Ouchi N, Parker JL, Lugus JJ, Walsh K: Adipokines in inflammation and metabolic disease. Nat Rev Immunol 2011;11:85-97.

- 3 Engin AB: Adipocyte-macrophage cross-talk in obesity. Adv Exp Med Biol 2017;960:327-343.

- 4 Luster AD: Chemokines--chemotactic cytokines that mediate inflammation. N Engl J Med 1998;338:436445.

5 Appari M, Channon KM, McNeill E: Metabolic regulation of adipose tissue macrophage function in obesity and diabetes. Antioxid Redox Signal 2018;29:297-312.

6 Boden G: Obesity and free fatty acids. Endocrinol Metab Clin North Am 2008;37:635-646, viii-ix.

- 7 Shi H, Kokoeva MV, Inouye K, Tzameli I, Yin H, Flier JS: Tlr4 links innate immunity and fatty acid-induced insulin resistance. J Clin Invest 2006;116:3015-3025.

8 Sindhu S, Al-Roub A, Koshy M, Thomas R, Ahmad R: Palmitate-induced mmp-9 expression in the human monocytic cells is mediated through the tlr4-myd88 dependent mechanism. Cell Physiol Biochem 2016;39:889-900.

9 Al-Rashed F, Kochumon S, Usmani S, Sindhu S, Ahmad R: Pam3csk4 induces mmp-9 expression in human monocytic thp-1 cells. Cell Physiol Biochem 2017;41:1993-2003.

10 Shihab PK, Al-Roub A, Al-Ghanim M, Al-Mass A, Behbehani K, Ahmad R: Tlr2 and ap-1/nf-kappab are involved in the regulation of mmp-9 elicited by heat killed listeria monocytogenes in human monocytic thp-1 cells. J Inflamm (Lond) 2015;12:32. 


\section{Cellular Physiology Cell Physiol Biochem 2019;52:212-224 \begin{tabular}{ll|l|l|l}
\hline DOI: 10.33594/000000015 & ( 2019 The Author(s). Published by
\end{tabular} and Biochemistry Published online: 28 February 2019 Cell Physiol Biochem Press GmbH\&Co. KG \\ Ahmad et al.: MIP-1 $\alpha$ Induction by Palmitate}

- 11 Jialal I, Kaur H, Devaraj S: Toll-like receptor status in obesity and metabolic syndrome: A translational perspective. J Clin Endocrinol Metab 2014;99:39-48.

- 12 Bunn RC, Cockrell GE, Ou Y, Thrailkill KM, Lumpkin CK Jr, Fowlkes JL: Palmitate and insulin synergistically induce il-6 expression in human monocytes. Cardiovasc Diabetol 2010;9:73.

- 13 Joshi-Barve S, Barve SS, Amancherla K, Gobejishvili L, Hill D, Cave M, Hote P, McClain CJ: Palmitic acid induces production of proinflammatory cytokine interleukin-8 from hepatocytes. Hepatology 2007;46:823830 .

- 14 Akash MSH, Rehman K, Liaqat A: Tumor necrosis factor-alpha: Role in development of insulin resistance and pathogenesis of type 2 diabetes mellitus. J Cell Biochem 2018;119:105-110.

- 15 Kochumon S, Wilson A, Chandy B, Shenouda S, Tuomilehto J, Sindhu S, Ahmad R: Palmitate activates ccl4 expression in human monocytic cells via tlr4/myd88 dependent activation of nf-kappab/mapk/ pi3k signaling systems. Cell Physiol Biochem 2018;46:953-964.

16 Huber J, Kiefer FW, Zeyda M, Ludvik B, Silberhumer GR, Prager G, Zlabinger GJ, Stulnig TM: Cc chemokine and cc chemokine receptor profiles in visceral and subcutaneous adipose tissue are altered in human obesity. J Clin Endocrinol Metab 2008;93:3215-3221.

17 Ahmad R, Al-Roub A, Kochumon S, Akther N, Thomas R, Kumari M, Koshy MS, Tiss A, Hannun YA, Tuomilehto J, Sindhu S, Rosen ED: The synergy between palmitate and tnf-alpha for ccl2 production is dependent on the trif/irf3 pathway: Implications for metabolic inflammation. J Immunol 2018;200:35993611.

- 18 Akira S, Takeda K: Toll-like receptor signalling. Nat Rev Immunol 2004;4:499-511.

- 19 Jiao P, Chen Q, Shah S, Du J, Tao B, Tzameli I, Yan W, Xu H: Obesity-related upregulation of monocyte chemotactic factors in adipocytes: Involvement of nuclear factor-kappab and c-jun nh2-terminal kinase pathways. Diabetes 2009;58:104-115.

$20 \mathrm{Xu}$ L, Kitade H, Ni Y, Ota T: Roles of chemokines and chemokine receptors in obesity-associated insulin resistance and nonalcoholic fatty liver disease. Biomolecules 2015;5:1563-1579.

- 21 Pillon NJ, Bilan PJ, Fink LN, Klip A: Cross-talk between skeletal muscle and immune cells: Muscle-derived mediators and metabolic implications. Am J Physiol Endocrinol Metab 2013;304:E453-465.

- 22 Schäffler A, Schölmerich J: Innate immunity and adipose tissue biology. Trends Immunol 2010;31:228-235.

- 23 Ahmad R, Al-Mass A, Atizado V, Al-Hubail A, Al-Ghimlas F, Al-Arouj M, Bennakhi A, Dermime S, Behbehani K: Elevated expression of the toll like receptors 2 and 4 in obese individuals: Its significance for obesityinduced inflammation. J Inflamm (Lond) 2012;9:48.

- 24 Erridge C, Samani NJ: Saturated fatty acids do not directly stimulate toll-like receptor signaling. Arterioscler Thromb Vasc Biol 2009;29:1944-1949.

- 25 Huang S, Rutkowsky JM, Snodgrass RG, Ono-Moore KD, Schneider DA, Newman JW, Adams SH, Hwang DH: Saturated fatty acids activate tlr-mediated proinflammatory signaling pathways. J Lipid Res 2012;53:20022013.

26 Firestein GS, Manning AM: Signal transduction and transcription factors in rheumatic disease. Arthritis Rheum 1999;42:609-621.

- 27 Guijarro-Munoz I, Compte M, Alvarez-Cienfuegos A, Alvarez-Vallina L, Sanz L: Lipopolysaccharide activates toll-like receptor 4 (tlr4)-mediated nf-kappab signaling pathway and proinflammatory response in human pericytes. J Biol Chem 2014;289:2457-2468.

28 Guo CJ, Douglas SD, Lai JP, Pleasure DE, Li Y, Williams M, Bannerman P, Song L, Ho WZ: Interleukin-1beta stimulates macrophage inflammatory protein-1alpha and -1beta expression in human neuronal cells (nt2-n). J Neurochem 2003;84:997-1005.

29 Li X, Tupper JC, Bannerman DD, Winn RK, Rhodes CJ, Harlan JM: Phosphoinositide 3 kinase mediates tolllike receptor 4-induced activation of nf-kappa b in endothelial cells. Infect Immun 2003;71:4414-4420.

30 Ojaniemi M, Glumoff V, Harju K, Liljeroos M, Vuori K, Hallman M: Phosphatidylinositol 3-kinase is involved in toll-like receptor 4-mediated cytokine expression in mouse macrophages. Eur J Immunol 2003;33:597605.

- 31 Volpe CM, Abreu LF, Gomes PS, Gonzaga RM, Veloso CA, Nogueira-Machado JA: The production of nitric oxide, il-6, and tnf-alpha in palmitate-stimulated pbmncs is enhanced through hyperglycemia in diabetes. Oxid Med Cell Longev 2014;2014:479587. 